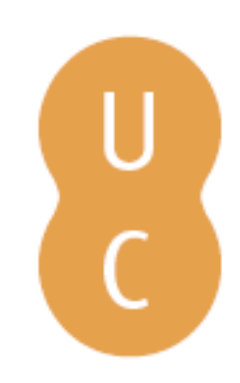

pommalina

\title{
Reliability metrics for the evaluation of the schedule plan in public transportation
}

$\begin{array}{ll}\text { Autor(es): } & \text { Sousa, Jorge Freire de; Mendes-Moreira, João; Moreira-Matias, Luís; } \\ \text { Gama, João }\end{array}$

Publicado por: Imprensa da Universidade de Coimbra

URL

persistente: URI:http://hdl.handle.net/10316.2/38153

DOI: $\quad$ DOI:http://dx.doi.org/10.14195/978-989-26-1039-9_7

Accessed : $\quad$ 26-Apr-2023 10:02:32

A navegação consulta e descarregamento dos títulos inseridos nas Bibliotecas Digitais UC Digitalis, UC Pombalina e UC Impactum, pressupõem a aceitação plena e sem reservas dos Termos e Condições de Uso destas Bibliotecas Digitais, disponíveis em https://digitalis.uc.pt/pt-pt/termos.

Conforme exposto nos referidos Termos e Condições de Uso, o descarregamento de títulos de acesso restrito requer uma licença válida de autorização devendo o utilizador aceder ao(s) documento(s) a partir de um endereço de IP da instituição detentora da supramencionada licença.

Ao utilizador é apenas permitido o descarregamento para uso pessoal, pelo que o emprego do(s) título(s) descarregado(s) para outro fim, designadamente comercial, carece de autorização do respetivo autor ou editor da obra.

Na medida em que todas as obras da UC Digitalis se encontram protegidas pelo Código do Direito de Autor e Direitos Conexos e demais legislação aplicável, toda a cópia, parcial ou total, deste documento, nos casos em que é legalmente admitida, deverá conter ou fazer-se acompanhar por este aviso.

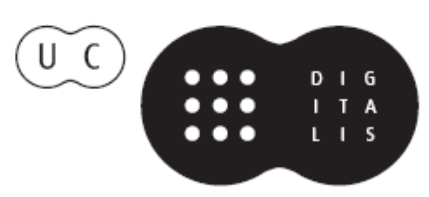


IMPRENSA DA UNIVERSIDADE DE COIMBRA

COIMBRA UNIVERSITY PRESS

\section{ASSESSMENT \\ METHODOLOGIES}

ENERGY, MOBILITY AND OTHER

REAL WORLD APPLICATION

\section{PEDRO GODINHO \\ JOANA DIAS}

EDITORS

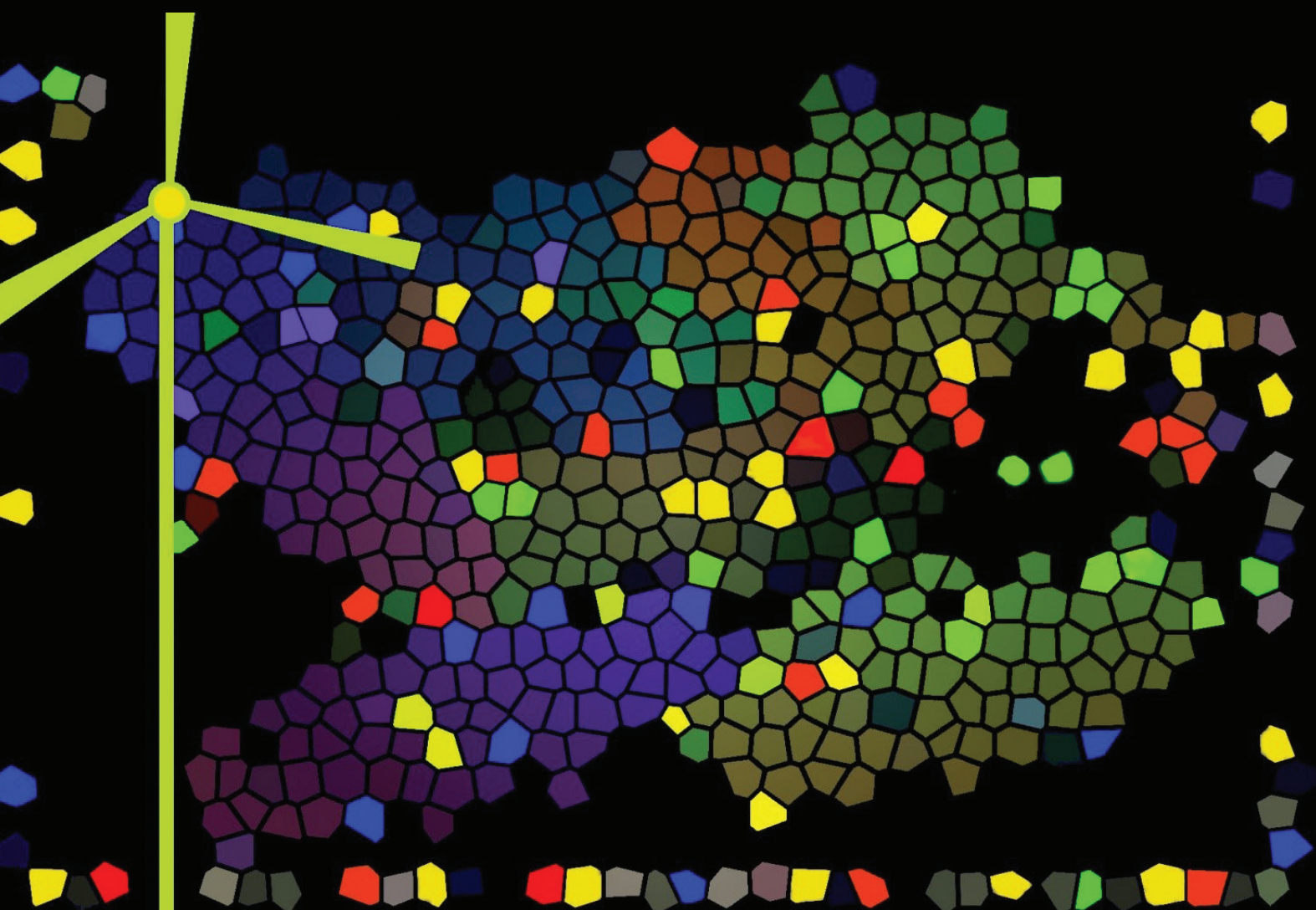




\title{
RELIABILITY METRICS FOR THE EVALUATION OF THE SCHEDULE PLAN IN PUBLIC TRANSPORTATION
}

\author{
Jorge Freire de Sousa ${ }^{1,2}$, João Mendes-Moreira ${ }^{3,4}$, \\ Luís Moreira-Matias ${ }^{5}$ and João Gama ${ }^{3,6}$
}

\begin{abstract}
Nowadays, the major Public Transportation Companies around the world use intelligent transportation systems based on automated data collection frameworks. The existence of these data has driven to the development of new approaches to the operational planning of public transportation. These approaches, commonly known as ADC-based operational planning strategies (ADC from Automated Data Collection), to improve public transportation reliability consist of adjusting the definitions made on the initial steps of the operational planning process by using real-world data. This type of changes concentrates mainly on restructuring routes and adjusting the existing schedule plan (SP). However, the usefulness of such tunings from a company point-of-view is often of difficult evaluation.

This paper starts by presenting a brief review on improving the network definition based on historical location-based data. Then, it presents a broad review on ADC-based evaluation techniques of the schedule plan reliability, discussing the existing metrics.
\end{abstract}

${ }^{1}$ CEgI-INESC TEC, 4200-465 Porto, Portugal

2 DEGI-FEUP, U. Porto, 4200-465 Porto, Portugal

3 LIAAD-INESC TEC, 4200-465 Porto, Portugal

${ }^{4}$ DEI-FEUP, U. Porto, 4200-465 Porto, Portugal

5 NEC Laboratories Europe, D-69115 Heidelberg, Germany

${ }^{6}$ Faculdade de Economia, U. Porto 4200-465 Porto, Portugal

e-mails: jfsousa@fe.up.pt, joao.mendes.moreira@inescporto.pt, luis.matias@neclab.eu, jgama@inescporto.pt 
The purpose of this paper is to critically describe the performance indicators used in the evaluation of the SP reliability, following the aforementioned bibliographic reviews. They will be certainly useful to shape the approaches developed by the research community for improving the quality of public road transportation operations based on data collected by ADC systems.

This paper focuses on two different, yet highly related, approaches: 1) changing the network definition; 2) evaluating and adjusting the SP in place. The automatic control strategies and the different actions to improve the SP remain out of the scope of this paper.

Keywords: Automated Data Collection (ADC); Operational Planning (OP); Public Transportation (PT); Network Design; Schedule Plan (SP); Reliability Metrics.

\section{Introduction}

In the last three decades, following a growing demand for fast transportation services in urban areas and clear advances both in real-time communications and in vehicle location technologies, public road transport companies have made important investments in information systems mostly dedicated to their operations (Furth et al., 2003; Barabino et al., 2013; Mazloumi et al., 2010; Hounsell et al., 2012). Automatic Vehicle Location (AVL), Automatic Passenger Counting (APC), Automatic Fare Collection (AFC), and multimodal traveler information systems are just some examples of this kind of answer from the operators to a major concern of reliability and service quality level from passengers. As a consequence of this effort in Advanced Public Transportation Systems, these companies have been able to collect massive data, indeed real continuous flows of data (Furth et al., 2003).

The existence of these new data has driven to the development of new approaches for planning the operations of public transport companies, and many researchers have highlighted their potential to offer insights on new ways to evaluate and improve service reliability by means of both operational planning (OP) and control (Strathman et al., 1999; Strathman, 2002; Strathman et al., 2003). Some of these approaches imply changes in 
the initial phases of OP. However, the usefulness of such changes from a company view-point is not always easy to assess (Mendes-Moreira \& de Sousa, 2014).

The aim of this paper is precisely to discuss works on the improvement of quality of public road transport operations based on OP strategies, mainly by using AVL and AFC data, and to improve the metrics and the approaches used in the evaluation of public transport reliability.

This paper starts with the presentation of how operational planning is usually done in public transport companies. Then, the next two sections are assigned to the review of literature; section 3 is dedicated to the alterations in the network design and section 4 to the evaluation of the schedule plan, both concerned with the reliability of the public transport service. Following the discussion presented in these two sections, challenges, opportunities and research ideas are proposed in section 5 . Finally, in section 6, some highlights and thoughts on future research trends are synthesized.

\section{Service and Operational Planning}

Service and OP at public transport companies include network and route design, frequency determination, and vehicle and crew scheduling (Ceder, 2002; Wilson et al., 2009):

a) Network definition: It consists of defining the lines, routes, and bus stops. Here, a route is an ordered sequence of directed road stretches between an origin and a destination, passing by multiple bus stops. A line is defined as a set of routes - typically two - with very similar paths, but inversely ordered.

b) Trips definition: The most common method involves firstly the definition of the set of bus stops for which schedule time-points will be set, necessarily including the origin and the destination ones. Then, timestamps are assigned to the previously defined schedule time-points. In high-frequency routes, however, this timetabling may also be defined by setting the time between two consecutive trips in the same route (this 
is called headway-based). The set of resulting trips is often defined as the schedule plan (SP).

c) Definition of duties: A duty is the work that a driver and/or a bus must perform in a day. The definition of the drivers' duties has much more constraints than the definition of bus duties (for instance, governmental legislation, union agreements and company rules). The logical definition of bus duties is commonly done prior to the drivers' duties.

d) Assignment of duties: It consists of physically assigning the previously defined logical duties to the companies' drivers and buses. The assignment of driver duties to drivers is called rostering.

Some authors (Vuchic, 2005; Ceder, 2007) also call this sequential or hierarchical process tactical planning. They claim that in the first stage of the process - the network design - decisions are less frequent; service considerations, judgement, and manual analysis tend to dominate. Going down the list, the dominance of these factors change up to the point where crew scheduling decisions are constantly made using cost considerations as the main driver and where computer-based analysis dominates in the optimization of the system (Aguerrebere, 2012).

Anyway, the data needed for this set of functions are extensive, encompassing all the inputs required for travel demand forecasting, as well as information on usage of the system and current route and network performance. And AVL and AFC data are most likely to be effective in characterizing this usage and the performance of the existing system (Wilson et al., 2009).

There are internal and external causes for reliability problems arising in PT networks. The former are usually associated to persistent problems as they include factors such as route configuration, inappropriate scheduling, times for the entry and exit of passengers at bus stops. The external ones are more sporadic. They include traffic congestion and accidents, raining days or badly parked cars. Only the internal causes are addressed by means of OP strategies, trying to avoid unreliability on a long-term perspective. The sporadic problems are lessened by control strategies, ensuring just corrective actions for a specific situation in a given moment (Abkowitz \& Tozzi, 1987). 
In this paper we will only concentrate our attention in the internal causes and in the ADC-based OP strategies to improve the reliability of PT operations by using real-world data, since they facilitate the analysis of the supply and demand, while allowing new network proposals. This type of approaches focuses on (a) altering routes or restructuring the network or on (b) adjusting the existing SP.

\section{On Modifying the Network Design}

As previously mentioned in section 2, the PT network design consists mainly of defining the number of routes to build, along with their paths and bus stops.

The importance of the design and planning of the network structure for PT success is usually undervalued, and surprisingly the topic is more or less neglected in standard texts on public transport or transport policy (Nielsen \& Lange, 2010). Maybe the infrequent nature of the network design can explain this underrating but getting the network right is usually more important than the often debated and studied mode selection.

Also, during the design stages of PT, little attention is paid to operational reliability, even if many design choices have a great influence on schedule observance. During the network design, reliability should be taken into account as a design parameter (Oort \& Nes, 2009a).

It is clear that the data obtained from ADC systems can have wide-ranging applications within public transport. One of them, of particular interest, is the opportunity to make use of these databases to develop a better picture of how public transport systems are performing and being used (Wilson et al., 2009). Better estimates of performance measures and usage attributes may be made at lower cost than by conventional methods, and, for the first time, it is possible to evaluate important attributes such as those concerned with reliability and its effects, until recently virtually impossible to quantify due to scarcity of data. Indeed, while there is an extensive bibliography about demand variations due to fare changes, findings on demand variations due to the level of service are occasional. 
There are a few AVL-based works focused on improving the PT reliability by adjusting the route definition. The most common approach is changing the location of the bus stops. The work in Yan et al. (2006) used historical GPS data to mine human mobility patterns in a major Taiwan intercity bus operation to find an optimal compromise between the location of bus stops and operational costs. The researchers did so by discovering the demand patterns using both a stochastic demand scheduling model and heuristic-based methods to solve the models. A passenger wait cost-based model is developed in Li and Bertini (2008) to find the optimal bus stop spacing based on historical AVL data.

More recently, a couple of works were published showing that many cost-effective opportunities to improve the level of service reliability, together with the application of operational instruments, both related to network structure, lead to highly reliable services.

In Oort and Nes (2009a), a tool is developed to calculate the additional waiting time due to variability and transfers based on actual journey and passenger data. A case study in The Hague shows that in the case of long lines with large variability, splitting the line could result in less additional travel time because of improved reliability. This benefit compensates for the additional transfer time, provided that the transfer point is well chosen.

Public transport network planners often propose network structures that either assume a certain level of regularity or are even especially focused on improving service reliability, such as networks in which parts of lines share a common route or the introduction of short-turn services. The key idea is that travelers on that route will have a more frequent transit service. The impact of such network designs on service regularity is rarely analyzed in a quantitative way.

Oort and Nes (2009b) present a tool that can be used to assess the impact of network changes on the regularity on a transit route and on the level of transit demand. The tool can use actual data on the punctuality of the transit system. The application of such a tool is illustrated in two ways. A case study on introducing coordinated services shows that the use of such a tool leads to more realistic estimates than the traditional 
approach. Second, a set of graphs is developed which can be used for a quick scan when considering network changes. These graphs can be used to assess the effect of coordinating the schedules and of improving the punctuality.

Nielsen and Lange (2010) try to demonstrate the importance of network planning and design for the success of public transport. They present proposals for the structuring of multi-modal public travel networks in different types of urban and rural districts, and they also give examples of "good" practices from different regions and countries.

Also, Oort et al. (2013) describe the state of publicly available transit data, with an emphasis on the Dutch situation. The value of insights from Automatic Vehicle Location data is demonstrated by examples. A software tool, that makes comprehensive operational analysis possible for operators and public transport authorities, was able to identify several bottlenecks when applied in practice.

\section{On Evaluating SP Reliability}

In this section, the authors decided to follow quite closely the terms of the survey presented in Moreira-Matias et al. (2015).

The SP reliability is a vital component for service quality. Improvements on reliability may increase the service demand and, consequently, the companies' profitability. Low reliability levels lead to a limited growth in the number of passengers and to a decreased perceived comfort (Strathman et al., 1999). It is possible to establish three distinct axes on evaluating SP reliability (Oort, 2011): 1) the unexpected increases on the waiting time on bus stops; 2) the time spent in crowded situations caused by transport overloading; and 3) delays on the passengers' arrivals due to travel time variability (TTV). The first two axes are mainly related with passengers' comfort and experience criteria. The value of such extra time consumptions varies from the passenger condition (seated or standing). However, these two aspects are mainly satisfiers: additional aspects that the passengers like to have but are not essential factors to abandon the 
services provided by a certain PT company. On the other hand, the last one is a fundamental issue by the disturbances that it does on the passengers' daily activities (Oort, 2011). By directly affecting the convenience and the speed of transportation, it is crucial to maintain the travelers' confidence on the PT network (i.e., a dissatisfier).

For the aforementioned reasons, this survey is focused on carrying the SP reliability evaluation by the existing TTV. Once established, it is expected that an SP meets the passengers' demand by following their mobility needs (namely, their daily routines). Typically, service unreliability is originated by one (or many) of the following causes (Fattouche, 2007; Cham, 2006): schedule deviations at the terminals, passenger load variability, running time variability, meteorological factors, and driver behavior.

Today's urban areas are characterized by a constant evolution of road networks, services provided, and location (for instance, new commercial and/or leisure facilities). Therefore, it is highly important to automatically assess how the SP suits the needs of an urban area. An efficient evaluation can lead to important changes in an SP. These changes will lead to a reduction in operational costs (for instance, by reducing the number of daily trips in a given route) and/or a reliability improvement in the entire transportation network, which will increase the quality of the passengers' experience and, therefore, the number of customers.

An SP consists of a set of $k$ schedules, which provide detailed information about every trip running on previously defined routes. Each schedule contains a timetable. Different routes may have different timetables. Nevertheless, they share the number $k$ of schedules and the daily coverage of each schedule.

A schedule planning process for a given route relies on three distinct steps: the first step is defining the number $k$ of schedules and their individual coverage; second, the schedule time-points are chosen among all bus stops in the route; and finally, the third step is defining timetables for each route schedule containing the time the buses pass at each scheduled time-point (per trip). This process is done for all routes.

From the aforementioned definition of SP, it is possible to divide the SP evaluation into two different dimensions: the suitability of the number 
of schedules $\mathrm{k}$ and of the set of their daily coverages and the reliability of their timetables (to test whether the real arrival times of each vehicle at each bus stop are meeting the previously defined timetable). Although there is an obvious impact on the definition of the timetable, to the authors' best knowledge, until very recently there was no research reported in the literature addressing the evaluation of the number of schedules and their daily coverage (Mendes-Moreira et al., 2015).

This section defines and reviews evaluation methodologies with regard to the reliability of timetables.

\section{Evaluation Metrics}

When evaluating an SP, it is important to differentiate low-frequency services and high-frequency services (Turnquist, 1982): in low frequency services, passengers arrive at the bus stops shortly before the bus's scheduled services, whereas in high-frequency services, the customers tend to arrive at the stops randomly (Jolliffe \& Hutchinson, 1975; Turnquist, 1978; Bowman \& Turnquist, 1981; Ceder \& Marguier, 1985). In the first scenario, punctuality is the main metric, whereas the service regularity is the most important metric in high-frequency routes. There is no exact boundary between these two scenarios. Fan and Machemehl (2000) conducted a data-driven experiment in Austin, Texas (USA), where they identified a 10-min threshold. Recent studies have also used 10-12 min as a threshold between low and high frequency services (Oort, 2011; Trompet et al., 2011).

Polus (1979) presented a landmark paper proposing four measures of performance for evaluating SP reliability on arterial routes: overall TT, congestion index, overall travel speed, and delay. All these measures were route based and highly focused on the operational perspective. The first three are mainly variations of the remaining ones - which are based on ratios between the actual and expected run times. Delay was a more sophisticated measure, defined as all the time consumed while traffic is impeded in its movement somehow - but also reported as hard to obtain by then. 
The AVL data enabled the possibility to extend this analysis to other granularities than route based such as segment based or stop based. Following such advances, four main indicators were first proposed by Nakanishi (1997) and followed by other similar studies (Strathman et al., 1999; Barabino et al., 2013). These indicators are outlined as follows: 1) on-time performance (OTP); 2) run time variation (RVT); 3) headway variation $(H V)$; and 4$)$ excess waiting time ( $E W T)$. The first two indicators are more applicable to low-frequency routes, whereas the last two focus on the high-frequency routes (Turnquist, 1982; Strathman, 1998; Strathman et al., 1999). This set of indicators is the most widely known formulations of these metrics, which have been used on multiple studies in the last decade. They are formally presented here.

OTP indicates the probability that buses will be where the schedule says they are supposed to be. It is possible to represent this metric by an arrival delay (AD) in a given trip i, i.e., $\mathrm{AD}_{i}$ as function of both the scheduled arrival time, i.e., $\mathrm{SAT}_{i}$, and the actual arrival time, i.e., $\mathrm{AAT}_{i}$. Therefore, it can be defined as follows (Strathman, 1998):

$$
\mathrm{AD}_{i}=\mathrm{AAT}_{i}-\mathrm{SAT}_{i} \text {. (1) }
$$

The RTV represents the variation on the run times performed by each trip. Some introductory concepts on this subject will be presented below. Typically, the TT reports the trip duration, from terminal to terminal, and is often referred to as round-trip time. TT is often used to define the time required to go from one point of interest to the other. This last definition is used in this survey. One of the factors that mostly affect the RTV is the dwell time, which is the total time the bus has to stay at a given bus stop for passenger boarding and alighting. From the passenger perspective, a larger variation can mean a longer waiting time in some stops and/or missed transfers. From the operational planners' perspective, greater RTV translates into higher costs as a result of the extra hours that must be added to accommodate passenger load (Strathman, 1998). This indicator is more appropriate for routes that cover long distances, facing many traffic lights and regular traffic delays (Sterman \& Schofer, 1976). Given a set of $n$ trips of interest, it is possible to compute the RTV as follows (Strathman et al., 1999): 


$$
\mathrm{RTV}=\mathrm{n}^{-1} \mathrm{x} / \sum_{i=1}^{n}\left|\mathrm{SAT}_{i}-\mathrm{AAT}_{i}\right| / \mathrm{AAT}_{i}(2)
$$

In high-frequency routes, where the trips start within very short headways, the OTP is not that relevant (Hounsell \& McLeod, 1998). The HV represents the probability that controllers are able to maintain a regular and stable headway between each pair of vehicles running in the same routes.

Let $f_{i, j}$ be the frequency (i.e., scheduled headway) established between a given pair of trips $(i, j)$, whereas $H_{i, j}^{b}$ represents the observed headway on such pair of trips at a bus stop of interest, i.e., $b$. The headway ratio on the bus stop b, i.e., $\mathrm{Hr}_{\mathrm{i}, \mathrm{j}}^{\mathrm{b}}$, is defined as follows (Strathman et al., 1999; Strathman, 1998):

$$
\mathrm{Hr}_{\mathrm{i}, \mathrm{j}}^{\mathrm{b}}=\left(\frac{H_{i, j}^{b}}{f_{i, j}^{b}}\right) \times 100
$$

where the value 100 represents a perfect SP matching. Given a set of $n$ trips of interest, it is possible to compute the standard deviation and the mean value of $\mathrm{Hr}\left(\sigma_{\mathrm{Hr}}^{\mathrm{b}}\right.$ and $\mu_{\mathrm{Hr}}^{\mathrm{b}}$, respectively). We can do it by calculating every possible $\mathrm{Hr}_{i, i+1}$ : $\mathrm{i} \in\{1, \ldots, \mathrm{n}-1\}$ at a bus stop $b$. Then, it is possible to obtain the HV at bus stop b throughout these $n$ trips as follows (Lesley, 1975):

$$
\mathrm{HV}^{b}=\left(\frac{\sigma_{\mathrm{Hr}}^{b}}{\mu_{\mathrm{Hr}}^{b}}\right)
$$

The EWT is an estimation of the excessive waiting time that passengers experience as a consequence of unreliable service. It is possible to calculate the EWT at a bus stop $b$, i.e., $\mathrm{EWT}^{b}$, as a function of $\mathrm{HV}^{b}$. A possible way to do so is presented as follows (Welding, 1957):

$$
\mathrm{EWT}^{b}=\left(\frac{\sigma_{\mathrm{Hr}}^{b}}{2 \times \mu_{\mathrm{Hr}}^{b}}\right)
$$

The bus stop $b$ used to compute statistics on the first two indicators is the destination bus stop. For the last two indicators, any bus stop can be considered a reference if it has a frequency scheduled to it, i.e., $f_{i, j}^{b}$. Commonly, such statistics are computed by the transit companies aggregating its values to a fixed time granularity (typically, 1-h periods) (Barabino et al., 2013), but they can be also computed according to the trip.

\section{SP Evaluation Studies}

Many works have evaluated schedule reliability by measuring the aforementioned indicators on historical AVL data sets. Strathman (1998) and Strathman et al. (1999) evaluated schedule reliability on the Tri-Met 
by measuring indicators (1-4), whereas the work by Bertini et al. (2003) solely focuses on the first two ratios. Traditionally, the HV was often disregarded by the transit planners due to the intrinsic chaos assumed (as the schedule time-points on the timetables are not the central variable to confirm service reliability). Nevertheless, recent advances have changed this reality: in Strathman et al. (2003), AVL/APC data were considered to evaluate the impact of the $\mathrm{HV}$ on the operational control. Another perspective of the Tri-Met data is presented in Berkow et al. (2007), where an analysis of indicators (2-4) demonstrated the feasibility of using AVL data along with other data sources to better accomplish their evaluation. Lin and Ruan (2009) formulated probabilistic headway regularity metrics (HV). Then, the authors tested their approach using AVL data from Chicago. In Bellei and Gkoumas (2010), relations between transit assignment, bus bunching events, and operation models are mined from the location-based data. This study aimed to identify irregularities in HV's distribution function caused by an inadequate SP. The reliability of an express service implemented in Montreal, Canada, is evaluated in El-Geneidy and Surprenant-Legault (2010) by employing the first two indicators. A large-scale evaluation was performed by Hounsell et al. (2012), where the data acquired through the iBus (an AVL/APC framework installed on a bus fleet running in the city of London, U.K.) were used to evaluate all the four main indicators of schedule reliability.

Another approach to evaluate schedule reliability on a route is the segment-based one. It consists of identifying segments/parts of a route where there are greater schedule deviations, and therefore, the SP should be adjusted by changing the timetable or by introducing bus priority lanes and/or traffic signals in intersections. One of the first authors to carry out such work was Horbury (1999) based on the HV. In Mandelzys and Hellinga (2010), it is proposed to measure indicators (1 and 2) using stop-based metrics and to identify the causes for larger deviations through an empirical framework. The work of El-Geneidy et al. (2011) proposes a way of identifying where the schedule is unreliable by evaluating the first two indicators on the schedule time-points. 
Recently, the methodological approach to evaluate SP reliability has evolved from the key indicators to using nonparametric deterministic methods such as data envelopment analysis (DEA), as described in Mendes-Moreira and de Sousa (2014). The main advantage enabled by employing such a method is the possibility of directly comparing metrics from distinct dimensions by introducing decision-making units. Lin et al. (2008) used AVL data to establish confidence intervals for the DEA scores based on the four indicators previously introduced. Despite its usefulness in identifying cost-based relationships between the resources used and the service produced, the DEA models are not addressed in this survey as they usually use a wider scope of data on the companies' management than we do.

Many of the aforementioned works have often employed the four traditional transit measures to evaluate schedule reliability. Nevertheless, few works have been successful in identifying the factors behind poor performance measurements. Such measurements focus mainly on the passengers' perspective about the service. Recently, innovative approaches have emerged on this research topic, such as the day-to-day variability. Mazloumi et al. (2010) proposed to determine the nature and shape of TT distributions for different departure time windows at different times of the day, using data from a route running in Melbourne, Australia. Factors causing TTV in public transport are also explored using regression methods. A method for finding interesting contexts to justify RTV is proposed in Jorge et al. (2012): Distribution rules are employed to identify particular conditions that lead to systematic bus delays. The HV is explored using a sequence mining approach in Moreira-Matias et al. (2012). The goal is to highlight sequences of bus stops where a failure to meet the schedule systematically leads to bus bunching situations further stops ahead in the route. Recently, an innovative study was presented by Chen et al. (2009), where three novel metrics were proposed to address three distinct granularities, namely, stop, route, and network levels. This approach seems promising. However, it also fails to deliver a unique indicator on the SP reliability. 
The contribution of this ongoing generator of historical trip data to evaluate SP reliability is that it replaces the old estimations on TTV with real values (Bertini \& El-Geneidy, 2003). The findings of the evaluations previously described consisted of identifying unreliable schedule time-points (El-Geneidy et al., 2011; Jorge et al., 2012) or badly designed bus priority lanes (Hounsell et al., 2012). In this work, some evaluations also build dwell time models that help to understand how this variable changes from trip to trip and throughout the day.

The four metrics are well established in the literature. However, they focus mainly on the passengers' perception of service quality, particularly the EWT. The OTP can help the planners identify the exact schedule time-points to be changed, whereas the RTV shows a more general perspective on network service, which can lead to more profound studies on the drivers' behavior, terminal dispatching policies, or on the current schedule's slack. The HV is the most used metric. Even so, it is possible to observe that the company's perspective on such RTV is not addressed as a primary goal of these evaluation studies.

Nevertheless, even if it is possible to identify what is happening and where changes must be performed to improve SP reliability, it is not easy to identify how it is possible to improve it.

\section{Research Challenges}

Two main issues may be identified where further AVL-based research should be employed to improve the evaluation of SP reliability: (a) creating a unique evaluation indicator, considering the company's perspective on the evaluation by including external factors in the evaluations or by developing cost-related evaluations and to (b) evaluate the reliability of the current schedule's number and coverage.

The aforementioned four evaluation metrics are classical but widely used in evaluation studies. However, distinct metrics (which are highly correlated to the main ones) are continuously emerging. It is known that the importance of each one of these indicators depends on the frequency established 
in the route. However, to the author's best knowledge, there is no consensual, individual, and integrated reliability ratio. This gap in the literature leads to an important research question: Is it possible to build a consensual frequency-dependent reliability ratio based on these four main indicators?

The first step in building an SP is defining both the schedule's number and day coverage. Then, a timetable is assigned to each schedule in a stepwise process already discussed. This definition has an explicit impact on the definition of timetables. However, to the authors' best knowledge, no research addresses the evaluation of whether the schedule's number and coverage still suit the current demand patterns and network behavior. Consequently, a question arises: Is it possible to assess whether the schedule's number and coverage are suitable for the network needs based on bistorical AVL data?

Another topic that can be a challenge is to rethink the OP. Section 2 briefly revises the steps of the traditional OP. Although AVL-based research has recently emerged on improving route definition, most AVL-based works on OP focus on the SP. The state of the art relies on deterministic and cost-based models. The AVL data make it possible to perform a bottom-up OP evaluation, namely, correctly exploring the available resources or even reducing them if possible to meet the current demand. A complete AVL-based framework to redesign all the steps of the OP is an intelligent transportation system (ITS) that could be a research goal on this topic for the medium-term future.

\section{Conclusion and Future Trends}

Over the last decade, various relevant contributions have emerged on location-based ITS applications for improving the OP of mass transit transportation networks. The spatiotemporal features of this type of data provided novel opportunities to reveal underlying patterns on unexpected behaviors that are deteriorating the quality of the service. These data are now affordable and widely available as a standard in every medium/ large-sized mass transit company. 
Such innovation revolutionized the way to improve both operational planning and control in these networks. The theoretical traffic models, which were the state of the art for improving OP during the 1980s and 1990s are now being progressively replaced by complex yet efficient statistical and machine learning models.

It is also important to provide real-time information to the passengers about what is bappening in the network (i.e., on-the-spot information on arrival times). More than building an exact but time-consuming prediction on arrival time, the researchers have focused on building simple frameworks capable of learning from location-based data streams and of providing predictions with low uncertainty.

The AVL-based improvements to planning and control are becoming increasingly mature, but the existing evaluation studies are still mainly proofs of concept focused on the passengers' perspective. Some challenges have been addressed in the previous section.

The high availability of reliable data reporting the vehicle operations in real time pushes up the will of researchers in this field. It is expectable that data driven models will prove themselves as state-of-the-art methods for improving PT reliability. More than ever, the AVL data are a real-time stream. Such availability, along with the expansion of urban centers, can progressively change the traditional focus on planning to an autonomous data-driven real-time control, which may reduce the manpower required for those tasks.

Acknowledgements: This work is financed by the FCT - Fundação para a Ciência e a Tecnologia (Portuguese Foundation for Science and Technology) within project UID/EEA/50014/2013

\section{References}

Abkowitz M. \& Tozzi, J., "Research contributions to managing transit service reliability," J. Adv. Transp., vol. 21, no. 1, 1987, pp. 47-65.

Aguerrebere, Carlos G. Q., Redesigning and improving the efficiency of bus transit networks using automatically collected data: the case of Gipuzkoa, Spain, MSc Thesis, Massachusetts Institute of Technology, Cambridge, MA, USA, 2012. 
Barabino, B., Di Francesco, M. \& Mozzoni, S., "Regularity diagnosis by automatic vehicle location raw data," Public Transp., vol. 4, no. 3, 2013, pp. 187-208.

Bellei, G. \& Gkoumas, K., "Transit vehicles' headway distribution and service irregularity," Public Transp., vol. 2, no. 4, 2010, pp. 269-289.

Berkow, M., Chee, J., Bertini, R. \& Monsere, C., Transit performance measurement and arterial travel time estimation using archived AVL data, presented at the ITE District 6th Annual Meeting, Portland, OR, USA, 2007.

Bertini, A. \& El-Geneidy, R., "Generating transit performance measures with archived data," Transp. Res. Rec.: J. Transp. Res. Board, vol. 1841, no. 1, 2003, pp. 109-119.

Bowman, L. \& Turnquist, M., Service frequency, schedule reliability and passenger wait times at transit stops," Transp. Res. Part A: Gen., vol. 15, no. 6, 1981, pp. 465-471.

Ceder, A. \& Marguier, P., "Passenger waiting time at transit stops," Traffic Eng. \& Control, vol. 26 , no. 6,1985 , pp. 327-329.

Ceder, A., "Urban transit scheduling: Framework, review and examples," J. Urban Planning Develop., vol. 128, no. 4, 2002, pp. 225-244.

Ceder, A., Public Transit Planning and Operation: Theory, Modeling and Practice. Oxford, U.K.: Butterworth-Heinemann, 2007.

Cham, L., Understanding Bus Service Reliability: A Practical Framework Using AVL/APC Data, Ph.D. dissertation, Massachusetts Institute of Technoogy, Cambridge, MA, USA, 2006.

El-Geneidy, A. \& Surprenant-Legault, J., "Limited-stop bus service: An evaluation of an implementation strategy," Public Transp., vol. 2, no. 4, 2010, pp. 291-306.

El-Geneidy, A., Horning, J. \& Krizek, K., "Analyzing transit service reliability using detailed data from automatic vehicular locator systems," J. Adv. Transp., vol. 45, no. 1, 2011 s pp. $66-79$.

Fan, W. \& Machemehl, R., "Characterizing bus transit passenger waiting times," in Proc. 2nd Mater. Specialty Conf. Can. Soc. Civil Eng., Montreal, QC, Canada, 2002, pp. 1-10.

Fattouche, G., Improving High-Frequency Bus Service Reliability through better Scheduling, Ph.D. dissertation, Massachusetts Institute of Technology, Cambridge, MA, USA, 2007.

Furth, P., Hemily, B., Muller, T. \& Strathman, J., Uses of Archived AVLAPC Data to Improve Transit Performance and Management: Review and Potential, Transportation Research Board, Ed. Washington, D.C., USA, 2003.

Horbury, A., "Using non-real-time automatic vehicle location data to improve bus services," Transp. Res. Part B: Methodol., vol. 33, no. 8, 1999, pp. 559-579.

Hounsell, N. \& McLeod, F., "Automatic vehicle location: Implementation, application, and benefits in the United Kingdom,” Transp. Res. Rec.: J. Transp. Res. Board, vol. 1618, no. 1, 1998, pp. 155-162.

Hounsell, N., Shrestha, B. \& Wong, A., "Data management and applications in a worldleading bus fleet," Transp. Res. Part C, Emerging Technol., vol. 22, 2012, pp. 76-87.

Jolliffe, J. \& Hutchinson, T., "A behavioural explanation of the association between bus and passenger arrivals at a bus stop," Transp. Sci., vol. 9, no. 3, 1975, pp. 248-282.

Jorge, A., Mendes-Moreira, J., de Sousa, J. F., Soares, C. \& Azevedo, P., "Finding interesting contexts for explaining deviations in bus trip duration using distribution rules," in Proc. IDA, 2012, pp. 139-149.

Lesley, L., "The role of the timetable in maintaining bus service reliability," in Proc. Operating Public Transp. Symp., 1975. 
Li, H. \& Bertini, R., "Optimal bus stop spacing for minimizing transit operation cost," in Proc. ASCE Traffic Transp. Studies, 2008, pp. 553-564.

Lin, J. \& Ruan, M., "Probability-based bus headway regularity measure," IET Intell. Transp. Syst., vol. 3, no. 4, 2009, pp. 400-408.

Lin, J., Wang, P. \& Barnum, D.,"A quality control framework for bus schedule reliability," Transp. Res. Part E: Logistics Transp. Rev., vol. 44, no. 6, 2008, pp. 1086-1098.

Mandelzys, M. \& Hellinga, B., "Identifying causes of performance issues in bus schedule adherence with automatic vehicle location and passenger count data," Transp. Res. Rec.: J. Transp. Res. Board, vol. 2143, no. 1, 2010, pp. 9-15.

Mazloumi, E., Currie, G. \& Rose, G., "Using GPS data to gain insight into public transport travel time variability,” J. Transp. Eng., vol. 136, no. 7, 2010, pp. 623-631.

Mendes-Moreira J. \& de Sousa, J.F., "Evaluating changes in the operational planning of public transportation", In Rossi, R. and de Sousa, J.F. (Ed.), Computer-based Modelling and Optimization in Transportation, vol. 262. New York: Springer-Verlag, 2014, pp. $57-68$.

Mendes-Moreira, J., Moreira-Matias, L., Gama, J. \& de Sousa, J.F., "Validating the Coverage of Bus Schedules: A Machine Learning Approach,” Information Sciences, Vol.293, 2015, pp.299-313.

Moreira-Matias, L., Ferreira, C., Gama, J., Mendes-Moreira, J. \& de Sousa, J. F., "Bus bunching detection by mining sequences of headway deviations," in Advances in Data Mining. Applications and Theoretical Aspects, vol. 7377. Berlin, Germany: Springer, 2012, ser. LNCS, pp. 77-91.

Moreira-Matias, L., Mendes-Moreira, J., de Sousa, J.F. \& Gama, J., "Improving Mass Transit Operations by Using AVL-Based Systems: A Survey", IEEE Transactions on Intelligent Transportation Systems, pp.-, 2015.

Nakanishi, Y., "Bus performance indicators: On-time performance and service regularity," Transp. Res. Rec.: J. Transp. Res. Board, vol. 1571, 1997, pp. 1-13.

Nielsen, G. \& Lange, T., Network Design for Public Transport Success: Theory and Examples, presented at the Thredbo Transport conference, 2010.

Oort, N. van \& Nes, R. van, "Line length vs. Reliability: network design dilemma in urban public transport", Transportation Research Record: Journal of the Transportation Research Board, Vol. 2112, Issue 1, 2009a, pp. 104-110.

Oort, N. van \& Nes, R. van, "Regularity analysis for optimizing urban transit network design", Public Transp., vol. 1, no. 2, 2009b, pp. 155-168.

Oort, N. van, Service reliability and urban public transport design, Ph.D. dissertation, Netherlands TRAIL Research School, Delft, The Netherlands, 2011.

Oort, N. van, Sparing, D., Brands, T. \& Goverde, R., Optimizing Public Transport Planning and Operations Using Automatic Vehicle Location Data: The Dutch Example. In: 3rd International Conference on Models and Technologies for Intelligent Transport Systems, Dresden, Germany, 2013, pp. 291-300.

Polus, A., "A study of travel time and reliability on arterial routes," Transportation, vol. 8, no. 2, 1979, pp. 141-151.

Strathman, J., Automated Bus Dispatching, Operations Control and Service Reliability: Analysis of Tri-Met Baseline Service Date, University of Washington, Seattle, WA, USA, Tech. Rep., 1998.

Strathman, J., Kimpel, T. \& Dueker, K., "Automated bus dispatching, operations control and service reliability," Transp. Res. Rec., vol. 1666, 1999, pp. 28-36. 
Strathman, J., Kimpel, T., Callas, S. \& Northwest, T., Headway deviation effects on bus passenger loads: Analysis of Tri-Met's archived AVLAPC data, Citeseer, State College, PA, USA, Tech. Rep., 2003.

Strathman, J., Tri-Met's experience with automatic passenger counter and automatic vehicle location systems, Center Urban Studies, Portland State Univ., Portland, OR, USA, 2002.

Trompet, M., Liu, X. and Graham, D., "Development of key performance indicator to compare regularity of service between urban bus operators," Transp. Res. Rec.: J. Transp. Res. Board, vol. 2216, no. 1, 2011, pp. 33-41.

Turnquist, M., "A model for investigating the effects of service frequency and reliability on bus passenger waiting times," Transp. Res.Rec., vol. 663, 1978, pp. 70-73.

Turnquist, M., Strategies for improving bus transit service reliability, Transportation Research Board, Washington DC, USA, Tech. Rep., 1982.

Vuchic, V.. Urban Transit. Wiley, 2005.

Welding, P., "The instability of a close-interval service," OR, vol. 8, no. 3, 1957, pp. 133-142.

Wilson, N., Zhao, J., \& Rahbee, A., "The potential impact of automated data collection systems on urban public transport planning", In Wilson, N. and Nuzzolo, A. (Ed.), Schedule-Based Modeling of Transportation Networks: Theory and Applications. New York: Springer, 2009, pp. 75-99.

Yan, S., Chi, C. \& Tang, C., "Inter-city bus routing and timetable setting under stochastic demands," Transp. Res. Part A: Policy Practice, vol. 40, no. 7, 2006, pp. 572-586. 
Série Investigação

Imprensa da Universidade de Coimbra

Coimbra University Press

2015

mais

Programa Operacional Regional do Centro

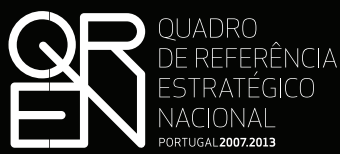

PORTUGAL 2007.2013

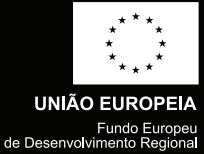

- $\mathbf{U}$

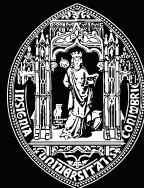

C •

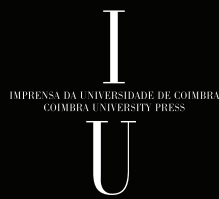

